\title{
Nanoparticles and higher plants
}

\author{
Ruffini Castiglione Monica and Roberto Cremonini ${ }^{1 *}$ \\ ${ }^{1}$ Dipartimento di Biologia, Università di Pisa Via Luca Ghini 556126 Pisa - Italy
}

\begin{abstract}
Nanomaterials and nanotechnology have been widely applied in the world in this last decade. Nanotechnology provides the tool and the technological platforms for the study and transformation of biological systems. Few studies have focused on the effects and mechanisms of nanomaterials on plants. The results of these studies have been reported with the aim to provide further insight into connections between plants and nanomaterials.
\end{abstract}

Key words: Angiosperms, nanoparticles, nanotechnology.

\section{INTRODUCTION}

Nanoparticles (nano-scale particles $=$ NSPs) are atomic or molecular aggregates with at least one dimension between 1 and 100nm (BALL 2002; Roco 2003a), that can drastically modify their physico-chemical properties compared to the bulk material (NeL et al. 2006). It is worth noting that nanoparticles can be made from a fully variety of bulk materials and that they can explicate their actions depending on both the chemical composition and on the size and/or shape of the particles (BRUNNER et al. 2006).

Depending on the origin, a further distinction is made between three types of NSPs: natural, incidental and engineered. Natural nanoparticles have existed from the beginning of the earth' history and still occur in the environment (volcanic dust, lunar dust, mineral composites, etc.). Incidental nanoparticles, also defined as waste or anthropogenic particles, take place as the result of manmade industrial processes (diesel exhaust, coal combustion, welding fumes, etc.).

Engineered nanomaterials can be grouped into four type: 1 - carbon based materials, usually including fullerene, single walled carbon nanotube (SWCNT) and multiwalled carbon nanotubes (MWCNT); 2 - metal based materials such as quantum dots, nanogold, nanozinc, nanoalumi-

\footnotetext{
* Corresponding author: phone: +39050 2211318 - fax: +390502211309 e-mail: rcremonini@biologia.unipi.it
}

num and nanoscales metal oxides like $\mathrm{TiO}_{2}, \mathrm{ZnO}$ and $\mathrm{Al}_{2} \mathrm{O}_{3} ; 3$ - dendrimers which are nano-sized polymers built from branched units, capable of being tailored to perform specific chemical function; 4 - composites which combine nanoparticles with other nanoparticles or with larger bulk-type materials (LIN and XING 2007) and present different morphologies such as spheres, tubes, rods and prisms (JU-NAM and LEAD 2008).

Engineered nanomaterials have received a particular attention for their positive impact in improving many sectors of economy, including consumer products, pharmaceutics, cosmetics, transportation, energy and agriculture etc., and are being increasingly produced for a wide range of applications within industry (NOvACK and BUCHELI 2007; ROCO 2003b).

There is now an extensive debate about the risks and benefits of the many manufactured nanomaterials into the environment (USEPA 2007) and in order to evaluate their potential adverse effects on the ecosystems and on human health the scientific community is working with increasing attention to this topic. The literature on the ecotoxicity of nanoparticles and nanomaterials as well as the chemistry of both manufactured and natural NSPs is summarized in recent reports (HANDy et al. 2008a, b; Yu-NAM and LeAD 2008).

Because of their widespread use in consumer products it is expected that NSPs will find their way into aquatic, terrestrial and atmosphere environments, where their fate and behaviour are largely unknown. Therefore organisms and especially those that interact strongly with their imme- 
diate environments, are expected to be affected as a result to their exposition to NSPs. In the review of NAVARRO et al. (2008) three topics are underlined, 1: sources, transformation and fate of nanoparticles; 2 : biotransformation that engineered nanoparticles can experience in contact with algae, fungi and plants and then the enhance and fate of these organisms; 3 : the mechanism of engineered nanoparticles toxicity and their effect on organism and how these toxic effects might be transferred through food chains, thus affecting communities and whole ecosystems.

Even as there has been an increasing amount of research on the toxicity of NSPs to animal kingdom and bacteria, limited studies are available in higher plants.

\section{PLANT-NANOPARTICLES INTERACTIONS: THE STATE OF ART}

Higher plants strongly interact with their atmospheric and terrestrial environments and are expected to be affected as a results of their exposure to NSPs.

Studies on the toxicity of nanomaterials are still emerging and basically evidence several negative effects on growth and development of plantlets. These results are based on tests suggested and encoded by USEPA (1996), that consider studies on seed germination, root elongation, often accompanied by other evaluations on biomass changes and anatomical-histological studies, useful to evidence in situ symptoms of possible toxicity.

LIN and XING (2007) analysed phytotoxicity of five types of multiwalled nanoparticles at the level of seed germination and root growth in six higher plant species (Raphanus sativus, Brassica napus, Lolium multiflorum, Lactuca sativa, Zea mays and Cucumis sativus). Seed germination was not affected except for the inhibition of nanoscale zinc on Lolium multiflorum and nanoscale zinc oxide on Zea mays. Inhibition of root growth varied greatly among nanoparticles and plants and it is partially correlated to nanoparticles concentration. The authors concluded that the inhibition occurred during the seed incubation process rather than seed soaking stage.

Later, the same researchers team (LIN and XING 2008) analysed the cell internalization and the upward translocation of $\mathrm{ZnO}$ nanoparticles by Lolium perenne. In the presence of $\mathrm{ZnO}$ nanoparticles ryegrass biomass significantly reduced, root tip shrank and root epidermal and cortical highly vacuolated or collapsed cells. $\mathrm{ZnO}$ nano- particles greatly adhered onto the root surface and individual nanoparticles were observed present in apoplast and protoplast of the root endodermis and stele. Translocation factor of $\mathrm{Zn}$ from root to shoot remained very low under $\mathrm{ZnO}$ nanoparticles treatments. The authors evidenced that the phytotoxicity of $\mathrm{ZnO}$ nanoparticles was not directly correlated with their limited dissolution in the bulk nutrient solution or rizosphere.

Limited reports underline positive or no adverse effects of NSPs on higher plants. HonG et al. $(2005 \mathrm{a}, \mathrm{b})$ analysed the effects of nano- $\mathrm{TiO}_{2}$ (rutile) on the photochemical reaction of chloroplasts of Spinacia oleracea as a theoretical basis and technical approach for the agricultural application of NSPs. The obtained results evidenced that the nano $\mathrm{TiO}_{2}$ treatments induced an increase of the Hill reaction and of the activity of chloroplasts, which accelerated $\mathrm{FeCy}$ reduction and oxygen evolution. Moreover non cyclic photophosphorylation activity was higher that cyclic photophosphorylation activity. The explanation of these effects, on the opinion of the authors, could be that the nano- $-\mathrm{TiO}_{2}$ might enter the chloroplast and its oxidation-reduction reactions might accelerate electron transport and oxygen evolution. ZHANG et al. (2005) analysed the effects of nano- $\mathrm{TiO}_{2}$ and non nano- $\mathrm{TiO}_{2}$ on the germination and growth of naturally aged seeds of Spinacia oleracea by measuring the germination rate and the germination and vigor indexes. An increase of these indexes was observed at $0.25-4 \%$ nano- $\mathrm{TiO}_{2}$ treatments. During the growth stage the plant dry weight was increased as was the chlorophyll formation, the ribulose bisphosphate carboxylase/oxygenase activity and the photosynthetic rate. These results evidenced that the physiological effects were related to the nanometer-size particles. The authors reported also that the effects of non nano- $\mathrm{TiO}_{2}$ particles were not significant.

RACUCIU and CREANGa (2007) analysed the influence of magnetic nanoparticles coated with tetramethylammonium hydroxide on the growth of Zea mays plant in early ontogenetic stages. The authors affirmed that water based ferrofluid addition in culture medium represents a source of iron. The ironbased nanoparticles may have not only a chemical but also a magnetic influence on the enzymatic structures implied in the different stages of photosynthesis. Small concentrations of aqueous ferrofluid solution added in culture medium had a stimulating effect on the growth of the plantlets while the enhanced concentration of aqueous ferrofluid solution induced an inhibitory effect. 
GAO et al. (2006) evidenced, in nano-anatase $\mathrm{TiO}_{2}$ treated Spinacia oleracea, that Rubisco carboxylase activity was 2.67 times that of control Rubisco. Since in the photosynthesis the molecular mechanism of carbon reaction promoted by nano-anatase $\mathrm{TiO}_{2}$ was still not clearly understood, Xuming et al. (2008), by reverse transcription PCR and Northen blotting experiments, evidenced that Rubisco small subunits and Rubisco large subunit messenger RNAs were promoted in the nano-treated plants. Accordingly, the protein expression of Rubisco from the nano-anatase treated spinach was increased by $40 \%$ compared with the control.

Since the manufacture of nanosized materials may result in the discharge of amount of these materials into the environments, Doshi et al. (2008) analysed the transport of two types of nanosized alumin particles through sand column with associated environmental impacts on soil systems. The presence of nano alumin particles did not have a negative effect on the growth of Phaseolus vulgaris and Lolium perenne in the tested concentration range.

In order to understand the possible benefits of applying nanotechnology to agriculture, the first step should be to analyze penetration and transport of nanoparticles in plants.

It is ascertained that nanoparticles tagged to agrochemicals or to other substances could reduce the injury to plant tissues and the amount of chemicals released into the environment; a certain contact is however unavoidable, due to the strong interaction of plants with soil growth substrates.

GONZALEZ-MELENDi et al. (2008) illustrated the application of microscopy tools and techniques at different level of resolution to visualize and track the transport and deposition of nanoparticles inside the plants. The author used carbon-coated magnetic nanoparticles (carbon encapsulation provides biocompatibility and a large adsorption surface) in living plant as Cucurbita pepo and the results showed the presence of nanoparticles both in the extracellular space and within some cells.

BATTKE et al. (2008) analysed the uptake of Palladium (Pd) by Hordeum vulgare and the behaviour of $\mathrm{Pd}$ nanoparticles in nutrient solutions used to grow plants. Smaller and larger Pd particles were comparatively assessed and the results showed that Pd uptake, via the roots, depends on its particle diameter. Smaller Pd particles cause stress effects in leaves at low concentration in nutrient solution.

ZHu et al. (2008) showed that Cucurbita maxima growing in an aqueous medium containing magnetite nanoparticles can absorb, move and accumulate the particles in the plant tissues, on the contrary Phaseolus limensis is not able to absorb and move particles. Therefore different plants have different response to the same nanoparticles.

LEE et al. (2008) analysed toxicity and bioavailability of copper nanoparticles to the plants $\mathrm{Pha}$ seolus radiatus and Triticum aestivum employing plant agar test as growth substrate for homogeneous exposure of nanoparticles. Plant agar, which is soft gel, allows dispersion of NSPs, hardly water soluble, avoiding their precipitation. The growth rates of both plants were inhibited and as result of exposure to nanoparticles and the seedling lengths of tested species were negatively related to the exposure concentration of nanoparticles. Bioaccumulation is concentration dependent and the contents of NSPs in plant tissues increased with increasing NSPs concentration in growth media. Triticum aestivum showed a greater accumulation of $\mathrm{Cu}$ NSPs in its roots due to root morphology. Bioavailability was estimated by calculating the bioaccumulation factor defined as Cu NSPs concentration in the plants divided by the Cu NSPs concentration in the growth media.

The main damage to the ecosystem due to particulate deposition is related to the competition pattern alteration among the species that can result in a drastic effect in plant biodiversity: more sensitive species may be eliminated and growth, flowering and fructification of other species may be favoured.

Atmospheric particulate matter deposition on the leaves leads to remarkable alteration in the transpiration rates, thermal balance and photosynthesis. DA SILVA et al. (2006) showed that nanoparticles may enter leaf surface. The structural features of leaf of Byrsonima sericea and Psidium guineense such peltate trichomes and hypodermis probably formed a barrier reducing the penetration of metal ions into the mesophyll as observed by the lower iron leaf content and iron accumulation in trichomes.

Since penetration rates of foliar applied polar solutes are highly variable and the mechanism is not yet fully understood, EICHERT et al (2008) investigated in Allium porrum and Vicia faba size exclusion limits and lateral heterogeneity of the stomatal foliar uptake pathway for aqueous solutes and water-suspended nanoparticles. The results suggested that the stomatal pathway differ fundamentally from the cuticolar foliar uptake pathway.

Even if application of nanotechnology to biology have been mainly focused on animal science 
and medical research, nanotechnology can be applied to plant science research in order to analyze plant genomics and gene function as well as improvement of crop species. Mesoporous silica nanopartricles can enter animal cells by the endocytosis process (SLOWING et al. 2006) and these nanoparticles can act as containers for small molecules. TORNEY et al. (2007) showed a mesoporous silica nanoparticle system that can transport DNA and chemicals into isolated plant cells (protoplasts from Nicotiana tabacum culture) and intact leaves (Zea mays young embryos).

Since nanoparticles are introduced into the soil as a result of human activities, among the many fields that nanotechnology takes into consideration, it is also important to recall the analyses of the connections among nanoparticles, plants and soil where plants live and grow up. According to this viewpoint, SHAH and Belozerova (2009) analysed the influence of metal nanoparticles on the soil microbial community and germination of Lactuca seeds. The results showed a insignificant influence of the nanoparticles in the soil on the number of colony forming units confirming the results of TONG et al. (2007) and of NyBERG et al. (2008). On the contrary metal nanoparticles influence the growth of Lactuca seeds, this influence was tested by measuring the length of the root and shoot of the plant after 15 days of incubation. An increase if the shoot/root ratio compared to that of the control was evidenced.

HARRIS AND BALI (2008) investigated the limits of uptake and the distribution of silver nanoparticles in Brassica juncea and Medicago sativa. In contrast to Brassica juncea, Medicago sativa showed an increase in metal uptake with a corresponding increase in the substrate of metal concentration and exposure time. The silver nanoparticles were located in the nucleus and applying the definition of McGrath and ZhaO (2003) the authors suggested that both Medicago sativa and Brassica juncea were hyperaccumulators of silver.

Due to the ability of specific plant species to hyperaccumulate NPs without apparent physiological damages, at least in particular experimental conditions, plants may represent from one hand a potential transport pathway of NPs in the environment, from the other, in specific cases, a cost-effective alternative to clean up NPs contamination. Besides Medicago and Brassica, it is noteworthy to recall Cucurbita maxima and its capability to take up a significant amount of magnetite nanoparticles from liquid growth medium and to accumulate them within roots and leaves (ZHU et al. 2008).

\section{CONCLUDING REMARKS}

In recent years remarkable progress has been made in developing nanotechnology as showed by the mentioned reports. Moreover the growth of nanotechnology has led to the rapid development of commercial application which involves the use of a great variety of manufactured NSPs. The use of these organic and inorganic nanosized material may result in the discharge of these materials into the environment: major environmental receptors of nanomaterials will be soil, sediment and biosolids from wastewater treatment.

There are many gaps in our knowledge on the ecotoxicity of NPs and there are many unresolved problems and new challenges concerning the biological effects of these NSPs. It is worth noting that nanoparticles can be made from an huge variety of bulk materials and that they can explicate their actions depending on both the chemical composition and on the size and/or shape of the particles.

Compared to other contaminant, nanoparticles size plays important roles in the behaviour, in the reactivity and in the toxicity of NPs. Considering these aspects it is not strange to find both positive and negative effects of nanoparticles on higher plants. Given that nanotechnology industry is growing in a very fast way, there is a crucial urgency to perform further studies on the subject, in order to establish right regulation of nanomaterials over their use, confinement, and disposal.

\section{REFERENCES}

BALL P., 2002 - Natural strategies for the molecular engineer. Nanotechnology, 13: 15-28.

BattKe F., Leopold K., Maier M., Schidhalter U., AND SCHuster M., 2008 - Palladium exposure of barley uptake and effects. Plant biology, 10: 272-276.

Brunner T. I., Wick P., Manser P., Spohn P., Grass R. N., Limbach L. K., Bruinink A., and Stark W. J., 2006: In vitro cytotoxicity of oxide nanoparticles: comparison to asbestos, silica, and effect of particle solubility. Environental Science \& Technology, 40: 4374-4381.

Da silva L. C., Oliva M. A., Azevedo A. A., and De Araujo M. J., 2006 - Response of restinga plant species to pollution from an iron pelletization factory. Water, Air, and Soil Pollution, 175: 241-256.

Doshi R., Braida W., Christodoulatos C., Wazne M., AND O'Connor G., 2008 - Nano-aluminum: transport through sand columns and enviromental effects on plant and soil communication. Environmental Research, 106: 296-303. 
Eichert T., Kurtz A., Steiner U., AND Goldbach H.E., 2008 - Size exclusion limits and lateral heterogeneity of the stomatal foliar uptake patbway for aqueous solutes and water suspended nanoparticles. Physiologia Plantarum, 134: 151-160.

Gao F., Hong F., Liu C., Zheng L., Su M., Wu X., YANG F., Wu C., AND YANG P., 2006 - Mechanism of nano-anatase $\mathrm{TiO} 2$ on promoting photosynthetic carbon reaction of spinach. Biological Trace Element Research, 111: 239-253.

Gonzales-Melendi P., Fernandez-Pacheco R., Coronado M. J, Corredor E., Testillano P.S., Risueno M. C., Marquina C., Ibarra M. R., Rubiales D., and PereZ-DE-LuQue A. 2008 - Nanoparticles as smart treatment-delivery systems in plants: assessment of different techniques of microscopy for their visualization in plant tissues. Annals of Botany, 101: 187-195.

Handy R. D., Owen R., And Valsami-Jones E., 2008a - The ecotoxicology of nanoparticles and nanomaterials: current status, knowledge gaps, challenges and future nedds. Ecotoxicology, 17: 315-325.

Handy R. D., Von Der Kammer F., Lead J. R., HasSEllov M., Owen R., AND CRANE M., 2008b - The ecotoxicology and chemistry of manufactured nanoparticles. Ecotoxicology, 17: 287-314.

HARRIS A. T. AND BALI R., 2008 - On the formation and extent of uptake of silver nanoparticles by live plants. Journal of Nanoparticles Research, 10: 691-695.

Hong F., Zhou J., Liu C., Yang F., Wu C., Zheng L., AND YANG P., 2005a - Effects of Nano-TiO2 on photochemical reaction of chloroplsts of Spinach. Biological Trace Element Research, 105: 269-279.

Hong F., Yang F., Liu C., GaO Q., Wan Z., Gu F., Wu C., Ma Z., ZhOU J., AND Yang P., 2005b - Influence of nano-TiO2 on the chloroplast aging of spinach under light. Biological Trace Element Research, 104: 249-260.

LeE W.-M., An Y.-J., Yoon H., And Kwbon H.-S., 2008 - Toxicity and bioavailability of copper nanoparticles to the terrestrial plants mung bean (Phaseolus radiatus) and wheat (Triticum aestrivum): plant agar test for water-insoluble nanoparticles. Environmental Toxicology and Chemistry, 27: 1915-1921.

LIN D. AND XING B., 2007 - Phytotoxicity of nanoparticles: inbibition of seed germination and root growth. Environmental Pollution, 150: 243-250.

LiN D. AND XING B., 2008 - Root uptake and phytoxoxicity of $\mathrm{ZnO}$ nanoparticles. Environmental Science \& Technology, 42: 5580-5585.

McGrath S.P., ZHaO F.J., 2003 - Phytoextraction of metals and metalloids from contaminated soils. Current Opinion in Biotechnology, 14: 277-282.

Navarro E., Baun A., Behra R., Hartmann N. B., Filser J., Miao A., Quigg A., Santschi P. H., AND Sigg L., 2008 - Environmental behaviour and ecotoxicity of engineered nanoparticles to algae, plants and fungi. Ecotoxicology, 17: 372-386.

Nel A., Xia T., Madler L., AND Li N., 2006 - Toxic potential of materials at the nanolevel. Science, 311: 622-627.
Nowack B. AND Bucheli T. D., 2007 - Occurrence, bebaviour and effects of nanoparticles in the environment. Environmental Pollution, 150: 5-22.

Nyberg L., Turco R. F., AND Nies L., 2008 - Assensing the impact of nanomaterial on anaerobic microbial communities. Environmental Science \& Technology, 42: 1938-1943.

Racuciu M. AND CREANGA D. E., 2007 - TMA-OH coated magnetic nanoparticles internalized in vegetal tissues. Romanian Journal of Physics, 52: 395-395.

Roco M. C., 2003a - Broader societal issue of nanotechnology. Journal of Nanoparticle Research, 5: 181-189.

Roco M. C., 2003b - Nanotechnology: convergence with modern biology and medicine. Current Opinion in Biotechnology, 14: 337-346.

SHAH V. AND BELOZEROVA I., 2009 - Influence of metal nanoparticles on the soil microbial community and germination of lettuce seeds. Water, Air, and Soil Pollution, 97:143-148

Slowing L., Trewyn B.G., Lin V.S., 2006 - Effect of surface functionalization of MCM-41-type mesoporous silica nanoparticles on the endocytosis by buman cancer cells. Journal of. Americam. Chemistry Society, 128: 14792-14793.

Torney F., Trewyn, B. G., Lin, Y., And Wang, K., 2007 - Mesoporous silica nanoparticles deliver DNA and chemicals into plants. Nature Nanotechnology, 2: 295-300.

Tong Z.,Bischoff M,. Nies L., Applegate B., Turco R.F. 2007 - Impact of fullerene (C60) on a soil microbial community.. Environmental Science \& Technology, 51: 2985-2991.

USEPA 1996 - Ecological effects test guidelines (OPPTS 850.4200) Seed Germination Root Elongation Toxicity Test. Available from: http://www.epa. gov/publications.

USEPA 2007 - Nanotechnology white paper. Document Number EPA 100/B-07001 1 Febrary 2007, www.epa.gov/osa

Xuming W., Fengqing G., Linglan M., Jie L., Sitao Y., Ping Y., And Fashui H., 2008 - Effects of nanoanatase on Ribulose-1, 5-Bisphophate carboxylasel oxygenase mRNA expression in Spinach. Biological Trace Element Research, 126: 280-289.

Yu-NAM Y. AND LEAD R., 2008 - Manufactured nanoparticles: an overview of their chemistry, interactions and potential environmental implications. Science of the Total Environment, 400: 396-414

Zhang L., Hong F., Lu S., AND Liu C., 2005 - Effect of nano-TiO2 on strength of naturally aged seeds and growth of Spinach. Biological Trace Element Research, 105: 83-91.

Zhu H., Han J., XiaO J.Q., AND Jin Y., 2008 - Uptake, translocation and accumulation of manufactured iron oxide nanoparticles by pumpkin plants. Journal of. Environmental Monitoring, 10: 713-717.

Received March 25 ${ }^{\text {th }}$ 2009; accepted May $25^{\text {th }} 2009$ 